\title{
Colorectal cancer screening: Opportunistic or organized?
}

\author{
Linda Rabeneck MD MPH ${ }^{1}$, Paul C Adams MD $^{2}$, Editor-in-Chief
}

L inda Rabeneck is a Professor of Medicine and the former Director of the Division of Gastroenterology at the University of Toronto, Toronto, Ontario. She is now Regional Vice President, Cancer Care Ontario and Vice President, Regional Cancer Services, Sunnybrook \& Women's College Health Sciences Centre in Toronto. Dr Rabeneck is a Senior Scientist at the Institute for Clinical Evaluative Sciences in Toronto. Her main clinical and research interest is in colorectal cancer (CRC) screening.

PA: Can you explain your new program to coordinate colon cancer screening in Ontario? LR: Each province has the challenge of implementing an organized province-wide program for CRC screening. In Ontario, we have completed a pilot study of fecal occult blood testing (FOBT), and we have a proposal submitted to the Ministry of Health and Long-Term Care that requests funding to implement provincewide CRC screening based on FOBT. Key elements of the proposal include support for the necessary infrastructure, including colonoscopy hubs.

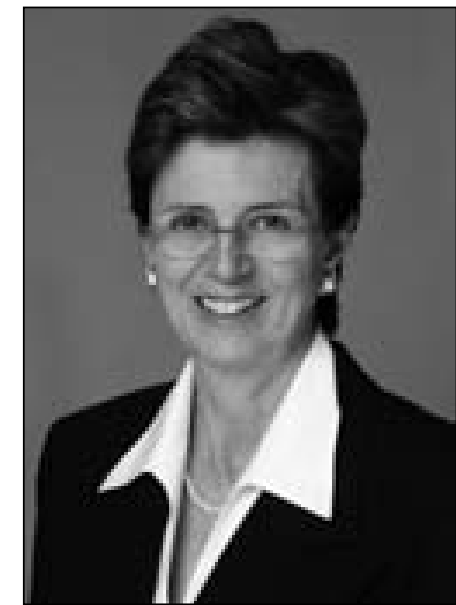

Linda Rabeneck is a Professor of Medicine at the University of Toronto and the former Director of the Division of Gastroenterology
PA: Flexible sigmoidoscopy (FS) by nonphysicians has been performed in many other places. Has it been successful? Have they moved on to doing colonoscopy? LR: We also have an initiative that is a partnership among the Change Foundation, the Michener Institute, Sunnybrook \& Women's College Health Sciences Centre and the Princess Margaret Hospital in Toronto, and Cancer Care Ontario, in which we are developing a training program for nurses to perform FS.

The goal of this initiative is to increase our capacity for CRC screening of average-risk individuals in the screen-eligible age group in Ontario. This has been a very successful approach in Kaiser Permanente in Northern California, which has had a nurse FS program in place since 1994 .

PA: Is there some sensitivity about turning over a revenuegenerating procedure to nonphysicians? In other specialties such as dialysis and cardiology, much of the work is performed by nurses and technicians, with revenue going to the physicians. This has allowed those groups to devote more time to cognitive work, research and teaching.

LR: This will depend on the funding model - there are several different ways in which this activity could be funded. FS rates have declined over the past decade in Ontario; the procedure is being somewhat neglected as gastroenterologists and general surgeons do increasing volumes of colonoscopy. Clearly there is an opportunity to increase our CRC screening capacity, by training nonphysicians to perform FS.

PA: Is the plan to eventually have sigmoidoscopy screening centres throughout Ontario? Will this generate a lot of colonoscopies that cannot be performed because of shortages of facilities?

LR: A nurse FS program could be sited at a colonoscopy hub. This will clearly generate a certain volume of colonoscopies - but if $10 \%$ or even $15 \%$ of persons who have a FS have an abnormal examination, and go on to require colonoscopy, this is fewer than the $100 \%$ that would have a colonoscopy if we were to use colonoscopy as the initial screening test in average-risk individuals. Clearly, the latter is not a viable option for a province-wide organized CRC screening program. There are 2.8 million individuals aged 50 to 74 years in Ontario this year. We would not have the resources to accomplish this task using colonoscopy as the initial screening test. Hence the turn to nurse-administered FS as one option.

PA: Can you explain the current practice of opportunistic screening and how it compares with the program that you are proposing?

LR: Opportunistic screening is what we are all doing now in Canada. This is completely ad hoc. It depends on either a general practitioner or the patient raising the issue, and because this often is not mentioned during an office visit, screening does not happen. For example, we know that less than $20 \%$ of screen-eligible individuals in Ontario are screened, using any method.

Organized screening would include, at a minimum, the following:

- invitations to screen targeted at the screen-eligible population;

- information technology infrastructure to support the screening program;

\footnotetext{
${ }^{1}$ Toronto Sunnybrook Regional Cancer Centre, Toronto; ${ }^{2}$ London Health Sciences Centre, London, Ontario

Correspondence: Dr Linda Rabeneck, Toronto-Sunnybrook Regional Cancer Centre, 2075 Bayview Avenue, T2-025, Toronto,

Ontario M4N 3M5. Telephone 416-480-4825, fax 416-480-5804, e-mail Linda.Rabeneck@sw.ca
} 
- timely access to screening and follow-up tests (colonoscopy);

- quality assurance (credentialing of endoscopist, measurement of colonoscopy adverse events, measurement of proportion of incomplete colonoscopies, etc); and

- tracking of clinical outcomes (CRC incidence, CRC stage, CRC mortality).

PA: If technical fees are introduced to cover the overhead costs for endoscopy, how will this change the landscape?

LR: Technical fees are one way of funding endoscopic services when they are delivered in nonhospital settings, such as offices. However, we need to be clear that simply putting technical fees in place does not constitute an organized screening program. The office endoscopy environment is currently completely unregulated. Technical fees, in and of themselves, will not solve this problem.

PA: Is Ontario an easier environment to try to implement an organized screening program than the United States?
LR: Any of our provinces - because we have single-payor, universal access health care systems - provide a good framework for implementation of an organized CRC screening program. In the United States, unless you are within a large system that has a single payor (such as the publicly funded Veterans Affairs Health Care System, or Kaiser Permanente, a large nonprofit health maintenance organization) this is very difficult, because health care funding is like a patchwork quilt with many payors, with different fee reimbursement structures and with differences in the services covered. In Canada, we are in an ideal position to move this forward.

PA: Can you predict the future of colon cancer screening in Ontario over the next decade?

LR: I believe we will begin to implement FOBT screening and that it will be phased in, adding geographical areas each year. In this way, we could have a full program implemented by year 5 . We will create colonoscopy hubs for the FOBTpositive persons to be followed up. We will also see sites at which nurse-administered FS is offered as an option for the initial screening test. 


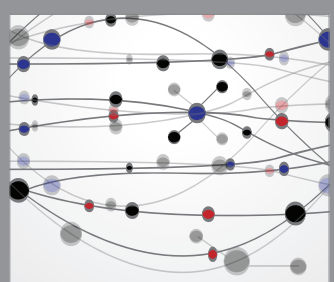

The Scientific World Journal
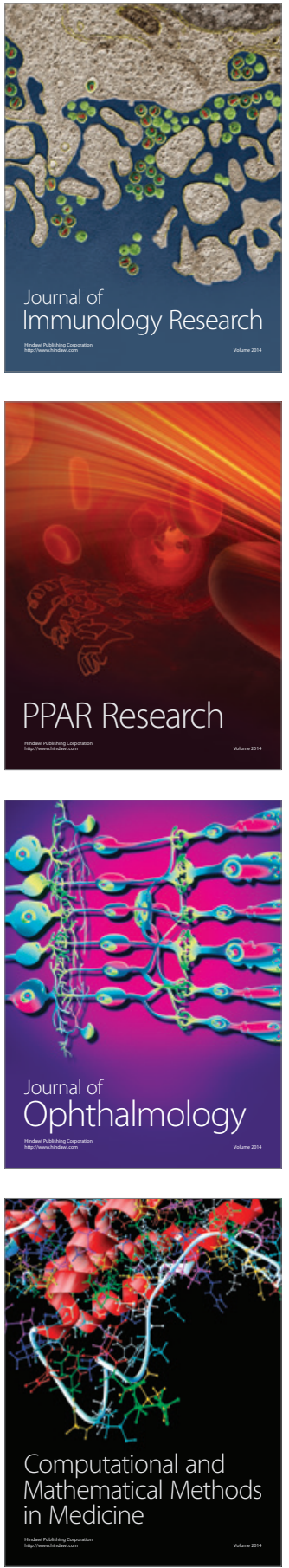

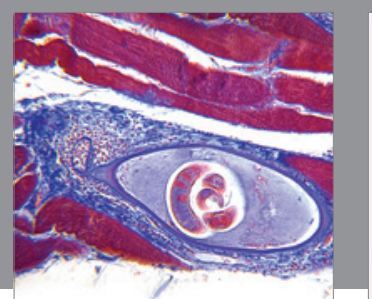

Gastroenterology Research and Practice

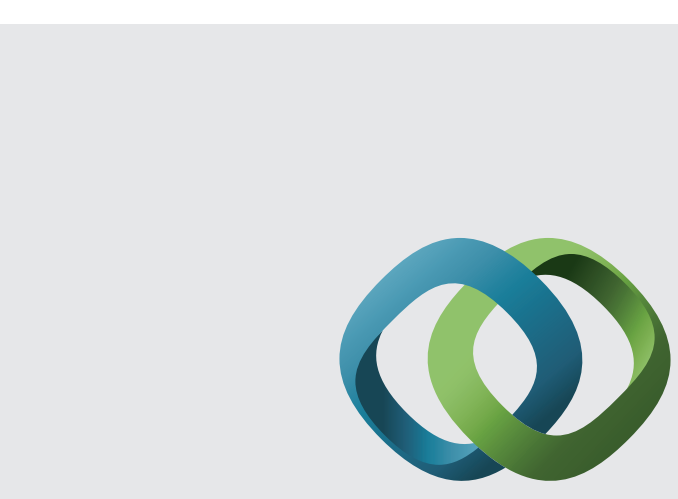

\section{Hindawi}

Submit your manuscripts at

http://www.hindawi.com
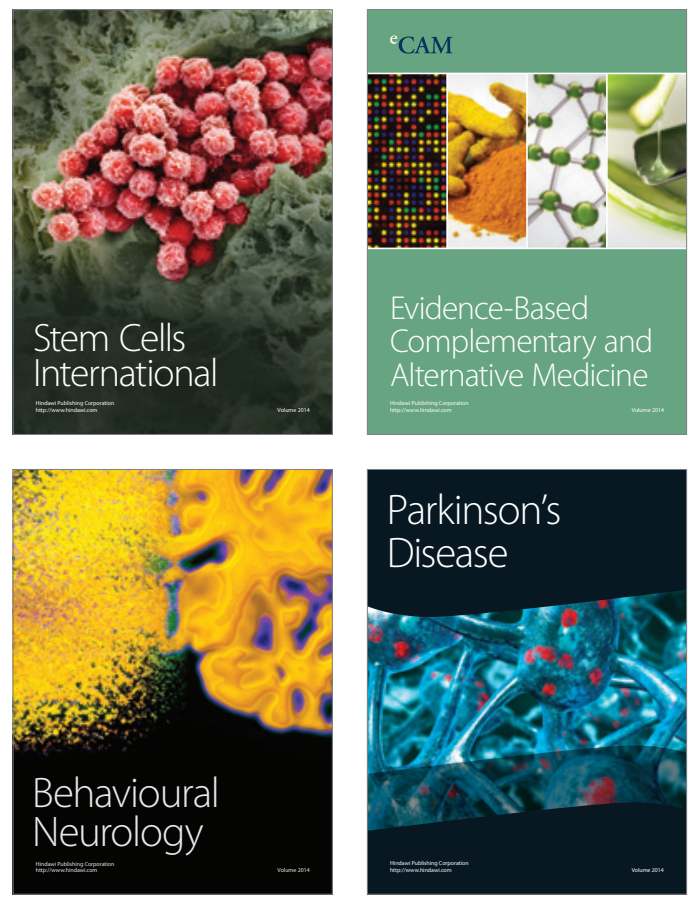
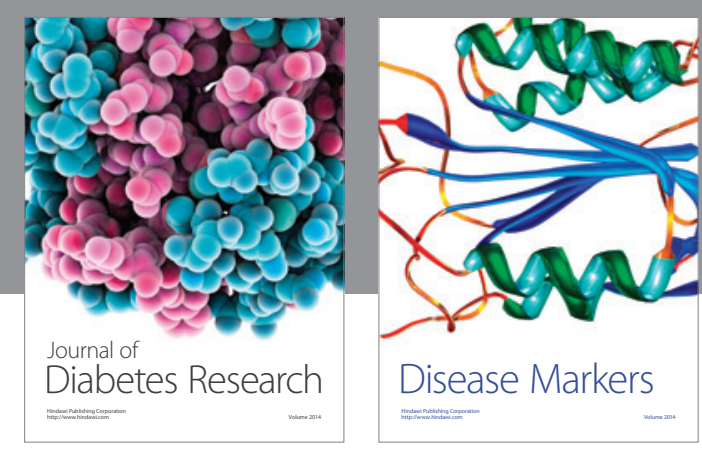

Disease Markers
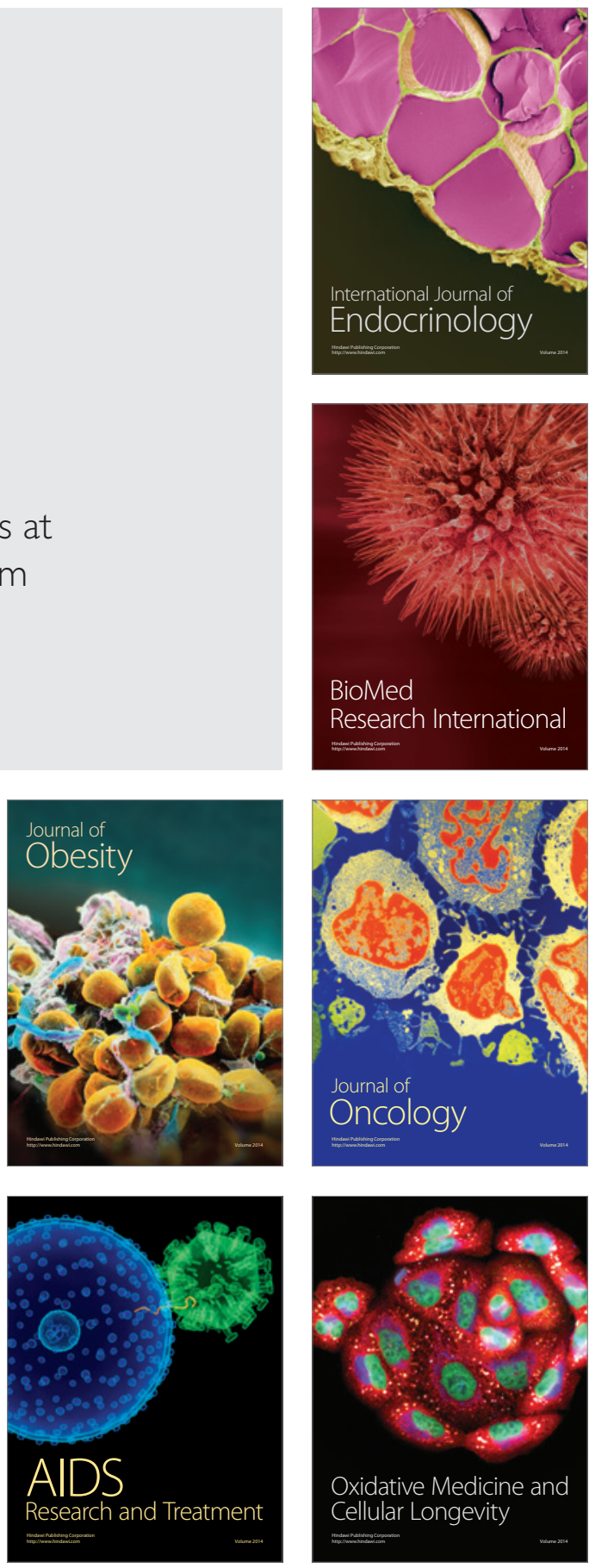